\title{
Aclimatização de mudas de cana-de-açúcar em ambiente protegido sob dois tipos de malhas de sombreamento
}

\author{
Cristiane Guiselini ${ }^{1}$, Heliton Pandorfi ${ }^{1}$, Andréa C. B. Barros ${ }^{2}$, \\ Luzia F. da Silva $^{3} \&$ Sinval P. O. da Silva Neto ${ }^{1}$
}

\begin{abstract}
RESUMO
Objetivou-se, com este trabalho, analisar a radiação solar global, a temperatura do ar e seus efeitos no crescimento e desenvolvimento de mudas de cana-de-açúcar em aclimatização sob dois tipos de cobertura em ambiente protegido. A pesquisa foi conduzida na área experimental do Centro de Tecnologias Estratégicas do Nordeste, Igarassu, PE. O ambiente protegido foi coberto com plástico leitoso associado a dois tipos de malhas de sombreamento: malha termorrefletora e malha preta; as variáveis estudadas foram: meteorológicas (radiação solar, temperatura do ar) e biométricas (comprimento do colmo, diâmetro do colmo, comprimento da folha, número de folhas, altura da planta e área foliar). Utilizaram-se 12 bandejas sendo escolhidos, aleatoriamente, quatro tubetes por bandeja por tratamento para o acompanhamento biométrico. $\mathrm{O}$ delineamento experimental foi inteiramente casualizado utilizando-se o teste de Tukey $(p<0,05)$ para comparação entre as médias das variáveis biométricas. O ambiente com malha termorrefletora proporcionou os melhores resultados de desenvolvimento das mudas em decorrência da maior disponibilidade de radiação solar global nesse ambiente de produção.
\end{abstract}

Palavras-chave: cultivo protegido, elementos meteorológicos, microclima

\section{Acclimatization of sugarcane seedlings in a greenhouse under two types of shading screens}

\begin{abstract}
This study aimed to analyse the global solar radiation, temperature and their effects on the growth and development of seedlings of sugarcane under acclimatization in two types of coverages in a protected environment. The study was conducted in the experimental area at the Center for Strategic Technologies in the Northeast - Igarassu, PE. The greenhouse was covered with white polyethylene and divided into two: one associated with the thermal reflector mesh and another associated with black mesh. The studied variables were: weather (solar radiation, air temperature) and biometric (stem length, stem diameter, leaf length, leaf number, plant height and leaf area). For biometric monitoring, 12 randomly selected trays with four tubes per tray per treatment were used. The experimental design was completely randomized, using the Tukey test $(p<0.05)$ for comparison between means. The environment under thermal reflector mesh provided the best results for seedling development because of greater availability of solar radiation in the production environment.
\end{abstract}

Key words: greenhouse, weather elements, microclimate

\footnotetext{
UFRPE, Rua Dom Manoel de Medeiros, s/n, Dois Irmãos, CEP 52171-900, Recife, PE. Fone: (81) 3320-6260. E-mail: cguiseli@hotmail.com; pandorfi@dtr.ufrpe.br; sinvalpeixoto@yahoo.com.br

${ }^{2}$ CETENE, Av. Professor Luiz Freire, 01, Cidade Universitária, CEP 50740-540, Recife, PE. Fone: (81) 3334-7200. E-mail: baltarbarros@gmail.com

${ }^{3}$ UAST/UFRPE, Fazenda Saco s/n, C.P. 63, CEP 56900-000, Serra Talhada, PE. Fone: (87) 3831-1927. E-mail: luzia@uast.ufrpe.br
} 


\section{INTRODUÇÃO}

A cana-de-açúcar Saccharum spp. é uma cultura bem adaptada às condições tropicais e subtropicais devido à alta disponibilidade de água, nutrientes e radiação. A multiplicação desta espécie é feita, tradicionalmente, por meio de colmos e algumas variedades não produzem sementes férteis (Tejera et al., 2007).

Nas regiões canavieiras do Brasil, como o litoral Norte do Nordeste, a disponibilidade de área para expansão da cultura de cana-de-açúcar está cada vez mais escassa sendo imprescindível o manejo adequado da cultura, em busca de maior produtividade e qualidade dos canaviais (Wiedenfeld \& Enciso, 2008).

A adoção de técnicas de propagação in vitro (micropropagação) é uma alternativa que possibilita a obtenção de mudas de cana-de-açúcar de variedades selecionadas, com alta qualidade fitossanitária, com influência direta na percentagem de sobrevivência, na velocidade de crescimento e na produção final. A utilização de mudas sadias pode aumentar a produtividade da cultura de 10 a $30 \%$ e a longevidade dos canaviais em 30\% (Lee et al., 2007).

O cultivo realizado em ambientes protegidos é uma das tecnologias que têm contribuído para a fase de aclimatização de mudas de cana-de-açúcar e que, após a realização desta etapa, as plântulas bem desenvolvidas, enraizadas e aclimatizadas estão adequadas para o plantio no campo (Lee et al., 2007). No interior do ambiente protegido ocorre atenuação das variações extremas dos elementos meteorológicos, que são desfavoráveis às culturas (Vasquéz et al., 2005), como a redução da radiação solar incidente (Buriol et al., 2005), velocidade do vento (Chavarria et al., 2008), alteração da temperatura do ar, do solo e da umidade relativa do ar (Reis et al., 2009).

A criação de condições microclimáticas adequadas para as culturas no interior dos ambientes protegidos pode ser obtida por meio de diversas técnicas em que as mais econômicas são aquelas que empregam o uso e a combinação de diferentes tipos de materiais de cobertura, a fim de controlar a radiação solar incidente no interior do ambiente protegido (Guiselini et al., 2010).

Leite et al. (2008) salientam que as malhas metalizadas por alumínio em ambas as faces, promovem a conservação de energia no ambiente e a reflexão de parte da energia solar. Os fios retorcidos promovem a difusão da luz, aumentam a eficiência de captura de energia pelas plantas e, consequentemente, a eficiência da fotossíntese.

Existem poucos trabalhos que relatam os detalhes do procedimento de transplantio e aclimatização de mudas de cana-de-açúcar, as dificuldades e as soluções encontradas durante este processo. A carência de informações é maior no caso de grandes quantidades de plantas num sistema comercial de micropropagação. Meyer et al. (2009) ressaltam que a aclimatização das plantas em larga escala não foi, por enquanto, um processo totalmente otimizado.

Diante do exposto objetivou-se analisar a radiação solar global e a temperatura do ar e seus efeitos no crescimento e desenvolvimento de mudas de cana-de-açúcar em aclimatização sob dois tipos de coberturas em ambiente protegido.

\section{Material e Métodos}

A pesquisa foi conduzida na área experimental do Centro de Tecnologias Estratégicas do Nordeste (CETENE) na Usina São José, situada no município de Igarassu, PE, latitude de $7^{\circ}$ 48'37,32” S, longitude de 34 59' 49,23" O e altitude de $34 \mathrm{~m}$. O clima da região é caracterizado como megatérmico (As) com precipitação de inverno e estação seca do verão até o outono, segundo classificação de Köppen (Pereira et al., 2002).

O período experimental foi de maio a dezembro de 2011 sendo 43 dias para caracterização da temperatura do ar (Tar, $\left.{ }^{\circ} \mathrm{C}\right)$ de $17 / 05$ a 28/06/2011 e 63 dias para a aclimatização das mudas de 06/10 a 07/12/2011.

$\mathrm{O}$ ambiente protegido apresentava dimensões de $48 \mathrm{~m}$ de comprimento, $12,8 \mathrm{~m}$ de largura e $3,5 \mathrm{~m}$ de pé-direito, o que totaliza uma área de $614,4 \mathrm{~m}^{2}$. sua estrutura era de ferro galvanizado e para o fechamento lateral foi utilizada malha de sombreamento preta $(30 \%)$.

$\mathrm{O}$ ambiente protegido foi coberto com plástico leitoso e dividido em dois tratamentos, tratamento A (TA) coberto com plástico leitoso associado à malha de sombreamento termorrefletora (50\%) instalada na superfície interna do filme plástico e tratamento $\mathrm{B}(\mathrm{TB})$ coberto com plástico leitoso associado à malha de sombreamento preta $(50 \%)$ instalada na altura do pé direito.

Por não haver divisão física entre os tratamentos (TA e TB), a Tar foi caracterizada antes da fase de aclimatização das mudas, durante o período de 42 dias (17/05 a 28/06/2011), a fim de se verificar a existência ou não de registros diferenciados entre os dois tratamentos. Foram utilizados dois sensores de Tar conectados a um datalogger e dispostos a $1,5 \mathrm{~m}$ do piso no TA e TB, respectivamente, com registro de dados a cada $15 \mathrm{~min}$. A relação funcional da Tar no TA em função da Tar no TB foi estabelecida por análise de regressão.

$\mathrm{Na}$ fase de aclimatização (06/10 a 07/12/2011) a produção, o manejo e a irrigação das mudas foram adotados conforme a orientação do CETENE, para ambos os tratamentos. O material vegetal utilizado foi constituído por plântulas da variedade RB867515 micropropagadas em biorreator de imersão temporária e selecionadas por tamanho e presença de sistema radicular. As plântulas utilizadas para aclimatização foram transplantadas para bandejas com 108 tubetes.

Com vista à caracterização das variáveis meteorológicas no interior do ambiente protegido registraram-se, continuamente, valores de radiação solar global $\left(\mathrm{Qg}, \mathrm{W} \mathrm{m} \mathrm{m}^{-2} \mathrm{MJ} \mathrm{m}^{-2} \mathrm{~d}^{-1}\right) \mathrm{e}$ temperatura do ar $\left(\mathrm{Tar},{ }^{\circ} \mathrm{C}\right)$, por meio de sensores instalados a $1,50 \mathrm{~m}$ de altura do piso conectados à plataforma automática de registro de dados meteorológicos; já em relação ao registro dos dados no ambiente externo, os sensores (Qg e Tar) foram instalados a $40 \mathrm{~m}$ de distância do ambiente protegido.

Os registros das variáveis da planta tiveram início uma semana após o plantio das mudas, no dia 13/10/2011 e ocorreram uma vez por semana, no período de 7, 14, 21, 28, $35,42,49$ e 56 dias após o plantio. Para as medições foram consideradas as seguintes variáveis das plantas: número de folhas (NF); altura da planta (AP) - a altura máxima, sem esticar a folha; comprimento do colmo (CC) - da parte basal da planta 
até a interseção da bainha da folha mais nova; diâmetro do colmo (DC) - no ponto médio do colmo; mortalidade (NPM) e percentual de sobrevivência $(\% \mathrm{~S})$; área foliar $(\mathrm{Aft})$ - método não destrutivo; estimou-se a área foliar $\left(\mathrm{Aft}_{\text {estimada }}\right.$ ) conforme Eq. 1:

$$
A_{\text {festimada }}=\mathrm{f} \cdot \mathrm{c} \cdot \mathrm{L}
$$

em que:

f - fator de forma para a correção da área foliar, 0,75 (Oliveira et al., 2007)

$$
\begin{aligned}
& \mathrm{C} \text { - comprimento, cm } \\
& \mathrm{L} \text { - largura, } \mathrm{cm}
\end{aligned}
$$

Sendo assim, a área foliar por tubete (Aft) foi calculada pela Eq. 2:

$$
\mathrm{A}_{\mathrm{ft}}=\mathrm{A}_{\text {f estimada }} \cdot \mathrm{NF}
$$

em que:

$\mathrm{A}_{\mathrm{f} \text { estimada }}$ - área foliar estimada, $\mathrm{cm}^{2}$; NF - número de folhas por tubete

O efeito das coberturas foi avaliado considerando-se a Qg e Tar, comparando-se os dados registrados nos tratamentos com os dados externos. Neste caso foram determinadas as diferenças médias dos valores registrados entre os dois tratamentos e a condição externa, assim como a relação entre elas. Para Tar foi estabelecida análise de regressão e os valores Qg foram comparados aos das variáveis da planta AP, NF e Aft.

Para as variáveis da planta NF, AP, CC, DC e Aft utilizaramse 12 bandejas com 108 tubetes cada uma, tanto para TA quanto para $\mathrm{TB}$, sendo escolhidos aleatoriamente quatro tubetes por bandeja. $\mathrm{O}$ delineamento experimental utilizado foi inteiramente casualizado e teste de Tukey $(\mathrm{p}<0,05)$ para comparação entre as médias.

A determinação do número de plantas mortas (NPM) e o percentual de sobrevivência $(\% \mathrm{~S})$ foi realizada, semanalmente, com a contagem das plantas mortas por tratamento obtendo-se o valor acumulado de NPM, com subsequente determinação do $\% \mathrm{~S}$.

\section{Resultados E Discussão}

A relação funcional entre a temperatura do ar no interior dos tratamentos apresentou coeficiente de determinação elevado $\left(R^{2}=0,99\right)$ o que indica boa associação linear entre as variáveis estudadas. O coeficiente angular $(0,987)$ descarta a necessidade de acompanhamento individualizado para a variável temperatura do ar nos tratamentos TA e TB, caracterizado pela homogeneidade entre os dois ambientes devido à ausência de barreira física (Figura 1).

Com base nos resultados, o elemento meteorológico temperatura do ar registrado no interior do ambiente protegido foi comparado ao ambiente externo considerado variável única para os dois tratamentos (Tar interna, ${ }^{\circ} \mathrm{C}$ ). Nota-se, na Figura 2, que as relações entre a Tar interna e externa resultaram em um coeficiente de determinação elevado $\left(\mathrm{R}^{2}>0,94\right)$ sinalizando boa associação linear entre as variáveis estudadas; observa-

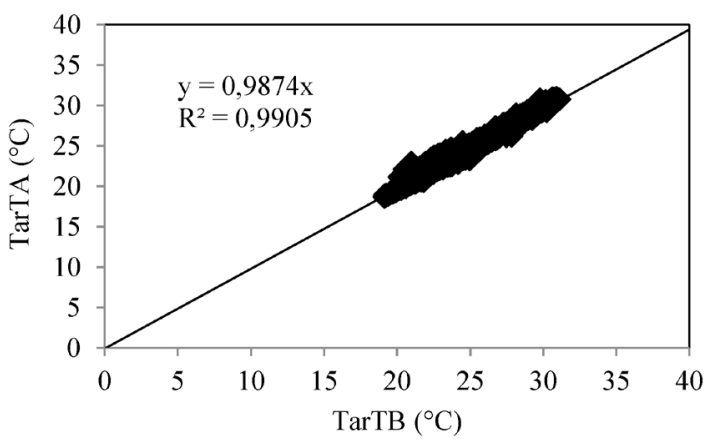

Figura 1. Relação entre a temperatura do ar (Tar) nos TA e TB, no período de 17/05/2011 a 28/06/2011

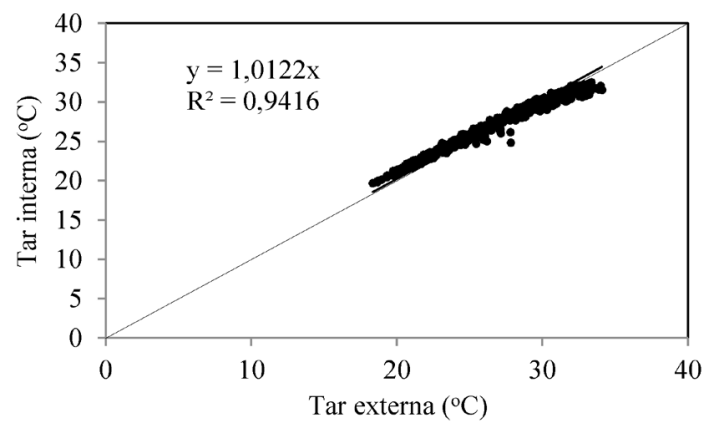

Figura 2. Relação entre a temperatura do ar (Tar) no ambiente protegido e ambiente externo

se, pelo coeficiente angular da equação, que os valores da Tar interna foram superiores em $1 \%$, quando comparados com a Tar externa.

A diferença entre os valores de temperatura do ar interno quando comparado ao externo $\left(\Delta \operatorname{Tar},{ }^{\circ} \mathrm{C}, \%\right)$ apresenta variação de acordo com a época do ano, o clima da região, a arquitetura do ambiente protegido, o tipo de cobertura, o tipo de fechamento lateral, o manejo de irrigação, o manejo das aberturas para ventilação e a vegetação de entorno. Tais variáveis proporcionam resultados de $\Delta$ Tar diferenciados em diversos estudos em ambiente protegido, como no presente trabalho, em que a Tar interna apresentou variação de 0,44 ${ }^{\circ} \mathrm{C}$, quando comparada com a do ambiente externo (Figura 3); Andrade Júnior et al. (2011) observaram, em Teresina, PI, valor médio de $\Delta$ Tar de $8,5 \%$ e Boueri \& Lunardi (2006) encontraram valor de Tar interna de $3,3^{\circ} \mathrm{C}$ acima do registrado no ambiente externo. Reis et al. (2009) salientam que o acréscimo nos valores da temperatura do ar pode ser desfavorável à cultura sob ambiente protegido.

$\mathrm{Na}$ fase de aclimatização a variação da Tar interna esteve sempre acima dos valores registrados externamente com valores médios da ordem de 26,28 e $25,84{ }^{\circ} \mathrm{C}$, respectivamente (Figura 3 ). Considerando que as plântulas foram mantidas em condição controlada no laboratório, com temperatura (Tar lab, ${ }^{\circ} \mathrm{C}$ ) entre 24 e $26^{\circ} \mathrm{C}$ e a faixa de temperatura do ar recomendada para a condução da cultura a céu aberto (Tar campo, ${ }^{\circ} \mathrm{C}$ ) ser de 20 a $30^{\circ} \mathrm{C}$. Marin et al. (2009) ressaltam que os valores médios em torno de $26,28^{\circ} \mathrm{C}$ no interior do ambiente protegido resultaram em uma mudança com menor estresse para a muda; quanto à Tar, pela pequena diferença média entre os ambientes: laboratório, ambiente protegido (aclimatização) e céu aberto (campo). Locatelli \& Lovato (2002) salientam que a fase de aclimatização 


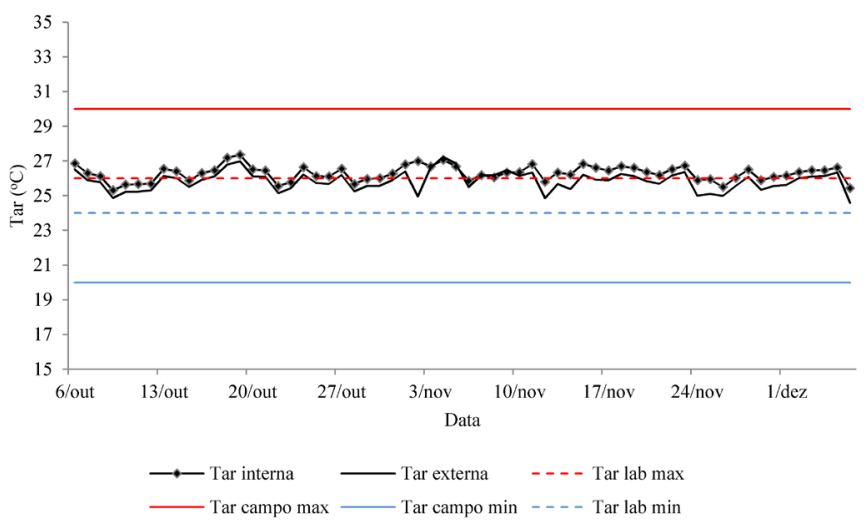

Figura 3. Temperatura do ar no laboratório (Tar lab max e min), valores de temperatura do ar máximo e mínimo recomendados para cultivo de cana-de-açúcar a campo (Tar campo max e min), temperatura média diária do ar no interior do ambiente (Tar interna) e no ambiente externo (Tar externa)

é crítica uma vez que a mudança do laboratório para o ambiente protegido implica em estresses que podem resultar em grandes perdas do material micropropagado.

A Figura 4 apresenta os valores médios de radiação solar global registrados nos ambientes estudados (QgTA e QgTB, $\mathrm{MJ} \mathrm{m}^{-2}$ semana $^{-1}$ ), ao longo de todo o período de aclimatização e comparados aos de área foliar $\left(\mathrm{Aft}, \mathrm{cm}^{2}\right)$ respectivamente.

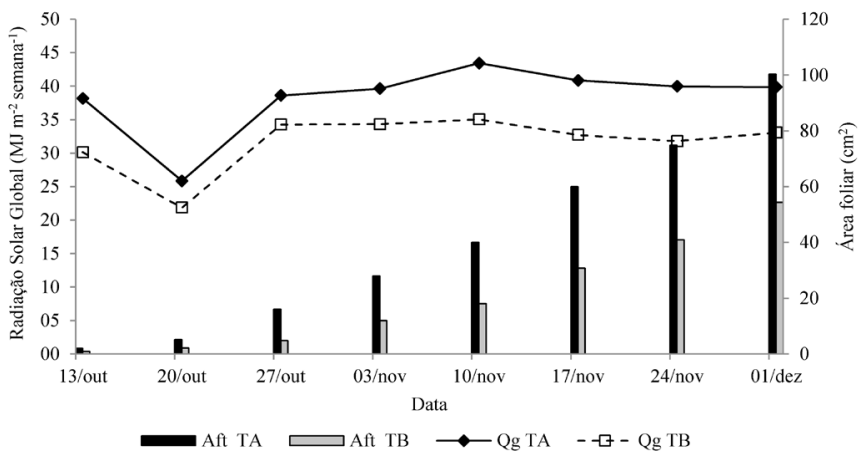

Figura 4. Variação semanal da radiação solar global e da área foliar total no ambiente com malha termorrefletora (TA) e malha preta (TB)

Nota-se que no ambiente com malha termorrefletora (TA) o valor médio semanal de QgTA foi da ordem de 37,66 MJ $\mathrm{m}^{-2} \operatorname{semana}^{-1}\left(5,38 \mathrm{MJ} \mathrm{m}^{-2} \mathrm{~d}^{-1}\right)$ e no ambiente com malha preta
(TB) de 31,15 $\mathrm{MJ} \mathrm{m}^{-2}$ semana $^{-1}\left(4,45 \mathrm{MJ} \mathrm{m}^{-2} \mathrm{~d}^{-1}\right)$. Assim, o TA proporcionou melhores condições de incidência e difusão da radiação solar no interior do ambiente protegido por apresentar valores mais próximos aos estabelecidos pela FAO (2011), para aclimatização de mudas de cana-de-açúcar, $58,80 \mathrm{MJ} \mathrm{m}^{-2}$ $\operatorname{semana}^{-1}\left(8,4 \mathrm{MJ} \mathrm{m}^{-2} \mathrm{~d}^{-1}\right)$.

Salienta-se que, ao comparar a radiação solar em TA e TB para o dia 10/Nov (35 dias após o plantio), nota-se maior diferença de Qg entre TA e TB, cerca de $8 \mathrm{MJ} \mathrm{m}^{-2}$ semana $^{-1}$ a mais em TA. Aliado a esta diferença, para o mesmo período, TA apresentou maior Aft que TB, assim como demais autores em estudos com outras culturas, como Guiselini et al. (2010) com gérbera e Souza Neto et al. (2010) com alface ao constatar a influência positiva da quantidade de radiação solar global na emissão e no tamanho de folhas.

Durante o período experimental houve, no TA, maior desenvolvimento das mudas em relação ao $\mathrm{TB}$, para todas as avaliações (número médio de folhas, NF; altura média das mudas, AP; área foliar, Aft; comprimento de colmo, CC e diâmetro de colmo, DC) de 7 a 56 dias após o plantio (Tabela 1), sendo que na última avaliação (56 dias após o plantio) o maior valor de NF de TB $(20,11 \mathrm{~cm})$ já tinha sido obtido em TA entre 41 e 48 dias após o plantio das mudas (17 e 24 de Nov), assim como o maior diâmetro do colmo em TB $(0,39 \mathrm{~cm})$ foi alcançado no final do experimento (01/ dez), ao passo que em TA observou-se valor desta ordem antes dos 41 dias após o plantio, que apresentou diâmetro de colmo de $0,40 \mathrm{~cm}$.

Devido à maior disponibilidade de radiação solar global no TA, quando comparado ao $\mathrm{TB}$, o TA promoveu alteração positiva no microclima do ambiente e nos processos fisiológicos da cultura, com possível ampliação do fluxo fotossintético e da taxa de aparecimento de folhas.

Santana et al. (2009) observaram, no cultivo de alface, que plantas sombreadas com malha preta tiveram seu crescimento reduzido quando comparadas com as plantas da malha termorrefletora evidenciando a ação do excesso de sombreamento sobre os processos fisiológicos da cultura, que reduz o fluxo fotossintético e o crescimento das mudas como repostas à atenuação da radiação solar. Guiselini et al. (2010) e Costa et al. (2011) verificaram, em pesquisas com diferentes culturas, gérbera e alface, respectivamente, que no ambiente protegido com malha termorrefletora ocorreram as maiores plantas com maior número de folhas.

Tabela 1. Número médio de folhas das mudas de cana-de-açúcar (NF), altura média das mudas (AP, cm), área foliar total $\left(\mathrm{Aft}, \mathrm{cm}^{2}\right)$, comprimento de colmo $(\mathrm{CC}, \mathrm{cm})$ e diâmetro de colmo $(\mathrm{DC}, \mathrm{cm})$ nos dois tratamentos, TA - Plástico leitoso + malha termorrefletora e TB - Plástico leitoso + malha preta, durante o período avaliado

\begin{tabular}{|c|c|c|c|c|c|c|c|c|c|c|}
\hline \multirow{2}{*}{ Data } & \multicolumn{2}{|c|}{ NF } & \multicolumn{2}{|c|}{$\mathrm{AP}(\mathrm{cm})$} & \multicolumn{2}{|c|}{ Aft $\left(\mathrm{cm}^{2}\right)$} & \multicolumn{2}{|c|}{ CC (cm) } & \multicolumn{2}{|c|}{$\mathrm{DC}(\mathrm{cm})$} \\
\hline & TA & TB & TA & TB & TA & TB & TA & TB & TA & TB \\
\hline $13 /$ out & $2,98 \mathrm{a}$ & $2,58 \mathrm{~b}$ & $6,66 \mathrm{a}$ & $5,54 \mathrm{~b}$ & $2,09 \mathrm{a}$ & $0,89 \mathrm{~b}$ & $1,70 \mathrm{a}$ & $1,00 \mathrm{~b}$ & $0,11 \mathrm{a}$ & $0,08 \mathrm{~b}$ \\
\hline 20 /out & $3,40 \mathrm{a}$ & $2,94 \mathrm{~b}$ & $8,85 \mathrm{a}$ & $6,67 \mathrm{~b}$ & $5,19 a$ & $2,13 b$ & $2,89 \mathrm{a}$ & $1,53 \mathrm{~b}$ & $0,15 \mathrm{a}$ & $0,13 b$ \\
\hline $27 /$ out & $4,15 \mathrm{a}$ & $3,42 b$ & $11,71 \mathrm{a}$ & $8,19 b$ & $16,09 \mathrm{a}$ & $4,81 \mathrm{~b}$ & $5,08 \mathrm{a}$ & $2,51 \mathrm{~b}$ & $0,22 \mathrm{a}$ & $0,18 b$ \\
\hline 03/nov & $4,54 \mathrm{a}$ & $4,13 \mathrm{a}$ & $14,73 \mathrm{a}$ & $9,79 \mathrm{~b}$ & $27,99 \mathrm{a}$ & $11,97 \mathrm{~b}$ & $6,78 \mathrm{a}$ & $3,96 \mathrm{~b}$ & $0,29 a$ & $0,23 b$ \\
\hline 10nov & $4,75 \mathrm{a}$ & $4,33 \mathrm{a}$ & $17,66 \mathrm{a}$ & $12,23 \mathrm{~b}$ & $40,02 \mathrm{a}$ & $18,01 \mathrm{~b}$ & $7,82 \mathrm{a}$ & $5,16 b$ & $0,34 \mathrm{a}$ & $0,28 \mathrm{~b}$ \\
\hline $17 /$ nov & $5,17 \mathrm{a}$ & $4,77 \mathrm{a}$ & $20,57 \mathrm{a}$ & $15,32 \mathrm{~b}$ & $59,99 \mathrm{a}$ & $30,76 \mathrm{~b}$ & $9,00 \mathrm{a}$ & $7,11 \mathrm{~b}$ & $0,40 \mathrm{a}$ & $0,32 \mathrm{~b}$ \\
\hline $24 /$ nov & $5,35 \mathrm{a}$ & $4,85 \mathrm{a}$ & $22,46 \mathrm{a}$ & $17,65 \mathrm{~b}$ & $74,89 \mathrm{a}$ & $40,96 \mathrm{~b}$ & $9,82 \mathrm{a}$ & $8,15 \mathrm{~b}$ & $0,46 \mathrm{a}$ & $0,35 \mathrm{~b}$ \\
\hline $01 / \mathrm{dez}$ & $5,65 \mathrm{a}$ & $4,88 \mathrm{~b}$ & $24,61 \mathrm{a}$ & $20,12 b$ & $100,28 \mathrm{a}$ & $54,33 \mathrm{~b}$ & $10,71 \mathrm{a}$ & $8,97 \mathrm{~b}$ & $0,52 \mathrm{a}$ & $0,39 \mathrm{~b}$ \\
\hline
\end{tabular}

Valores nas linhas seguidos das mesmas letras, não diferem estatisticamente entre si $(P>0,05)$, de acordo com o teste de Tukey 

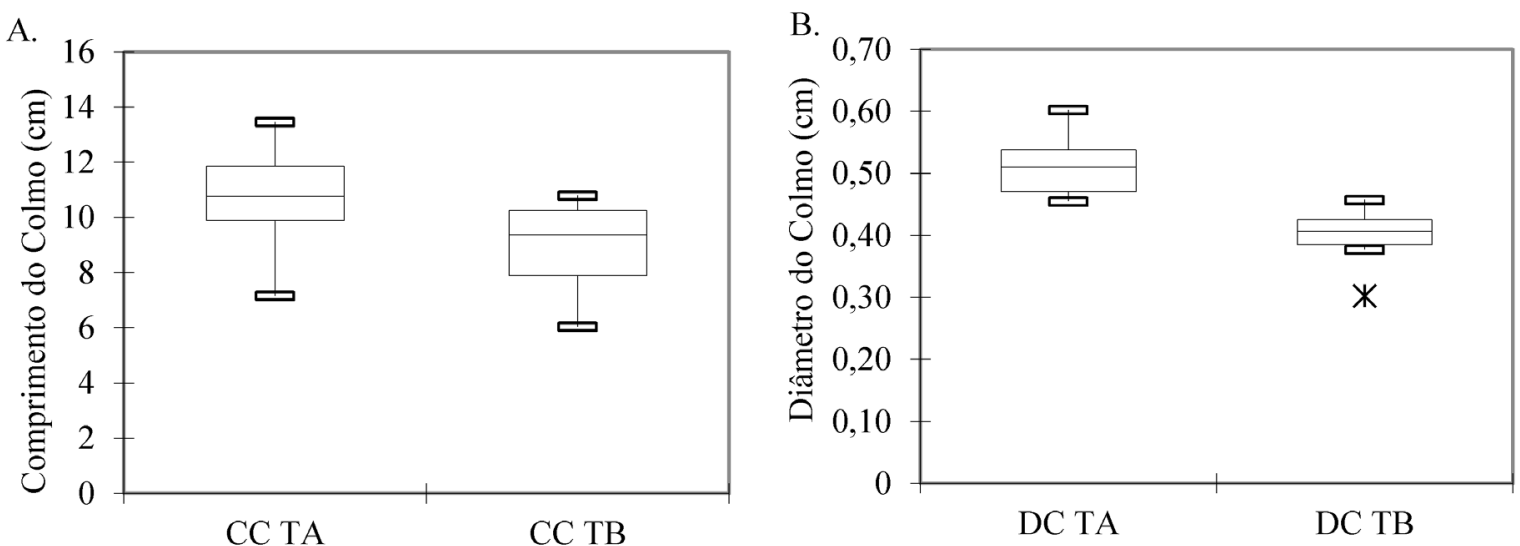

Figura 5. Comprimento de colmo $(\mathrm{cm})(\mathrm{A})$ - CC Diâmetro de colmo $(\mathrm{cm})-\mathrm{DC}$, nos ambientes protegidos: CC TA e DC TA - Plástico leitoso + malha termorrefletora e CC TB e DC TB - Plástico leitoso + malha preta, ao final do experimento

A maior variabilidade foi observada para CC TA(Figura 5A) e DC TA (Figura 5B), com diferença entre os valores extremos superiores e inferiores de $6 \mathrm{~cm}$ e $0,15 \mathrm{~cm}$ respectivamente enquanto para a CC TB e DC TB foi da ordem de $4 \mathrm{~cm}$ e $0,08 \mathrm{~cm}$; sendo assim, o TA disponibilizou um microclima mais adequado às plantas em que cada uma pode expressar seu potencial de desenvolvimento e no TB, por não oferecer um ambiente propício, as plantas apresentaram limitação no crescimento de colmo.

Quanto ao percentual de sobrevivência, as mudas submetidas ao TA apresentaram valor da ordem de $94 \%$, com perdas de 78 mudas. Este resultado foi superior quando comparado com o das mudas do TB, que apresentaram percentual de sobrevivência de 41,67\% (Tabela 2). Behera \& Sahoo (2009) obtiveram resultados inferiores ao TA, em torno de $85 \%$ de sobrevivência, após 30 dias de aclimatização, tal como Khan et al. (2008) cerca de $80 \%$ de sobrevivência, sendo esses percentuais resultado da diferença genotípica em resposta às alterações do microclima na aclimatização de mudas de cana-de-açúcar de cada estudo (Tabela 2).

Tabela 2. Número de plantas mortas (NPM) e percentual de sobrevivência (\%S) em cada semana de avaliação, nos dois ambientes de produção, TA - Plástico leitoso + malha termorrefletora e TB - Plástico leitoso + malha preta durante o período avaliado

\begin{tabular}{cccccc}
\hline \multirow{2}{*}{ Data } & \multicolumn{3}{c}{ TA } & & \multicolumn{2}{c}{ TB } \\
\cline { 2 - 3 } \cline { 5 - 6 } 13/out & NPM & \%S & & NPM & \%S \\
20/out & 14 & 98,92 & & 137 & 89,43 \\
27/out & 36 & 97,22 & & 323 & 75,02 \\
03/nov & 52 & 95,99 & & 514 & 60,34 \\
10/nov & 67 & 95,83 & & 719 & 44,52 \\
\hline
\end{tabular}

\section{CONClusÕES}

1. A temperatura do ar no interior do ambiente protegido atendeu à exigência das mudas na fase de aclimatização.

2. A malha termorrefletora $(50 \%)$ propiciou melhor crescimento e desenvolvimento das mudas de cana-de-açúcar e maior percentagem de sobrevivência em decorrência da maior disponibilidade de radiação solar global.

\section{Literatura CitADA}

Andrade Júnior, A. S.; Damasceno, L. M. O.; Dias, N. S.; Gheyi, H. R.; Guiselini, C. Climate variations in greenhouse cultivated with gerbera and relationship with external conditions. Engenharia Agrícola, v.31, p.857-867, 2011.

Behera, K. K.; Sahoo, S. Rapid in vitro sicro propagation of sugarcane (Saccharum officinarum L. cv-Nayana) through callus culture. Natureand Science, v.7, p.1-10, 2009.

Boueri, M. A.; Lunardi, D. M. C. Avaliação de elementos agrometeorólogicos no cultivo do cravo-de-defunto (Tagete ssp.) em ambiente protegido e a campo. Revista Energia na Agricultura, v.21, p.45-54, 2006.

Buriol, G. A.; Lago, I.; Heldwein, A. B.; Schneider, F. M.; Andriolo, J. L.. Disponibilidade de radiação solar para hortaliças cultivadas em ambiente protegido no período invernal no Estado do Rio Grande do Sul. Revista Brasileira de Agrometeorologia, v.13, p.21-26, 2005.

Chavarria, G.; Santos, H. P.; Felippeto, J.; Marodin, G. A. B.; Bergamaschi, H.; Cardoso, L. S.; Fialho, F. B. Relações hídricas e trocas gasosas em vinhedo sob cobertura plástica. Revista Brasileira de Fruticultura, v.30, p.1022-1029, 2008.

Costa, E.; Leal, P. A. M.; Rego, N. H.; Benatti, J. Desenvolvimento inicial de mudas de jatobazeiro do cerrado em AquidauanaMS. Revista Brasileira de Fruticultura, v.33, p.215-226, 2011.

FAO - Food And Agricultura Organization os the United Nations. Statistical data bases. Ano. 2011. <http://www. fao.org>. 19 Out. 2011.

Guiselini, C.; Sentelhas, P. C.; Pandorfi, H.; Holcman, E. Manejo da cobertura de ambientes protegidos: Radiação solar e seus efeitos na produção da gérbera. Revista Brasileira de Engenharia Agrícola e Ambiental, v.14, p.645-652, 2010.

Khan, S. A.; Rashid, H.; Chaudhary, M. F.; Chaudhry, Z.; Afroz, A. Rapid micropropagation of three elite Sugarcane (Saccharum officinarum L.) varieties by shoot tip culture. African Journal of Biotechnology, v.7, p.2174-2180, 2008.

Lee, T. S. G.; Bressan, E. A.; Silva, A. D. C. da; Lee, L. L. Implantação de biofábrica de cana-de-açúcar: riscos e sucessos. Revista Brasileira de Horticultura Ornamental, v.13, p.2032-2040, 2007. 
Leite, C. A.; Ito, R. M.; Lee, G. T. S.; Ganelevin, R.; Fagnani, M. A. Light spectrum management using colored nets to control the growth and blooming of phalaenopsis. Acta Horticulturae, v.770, p.177-184, 2008.

Locatelli, L. M.; Lovato, P. E. Inoculação micorrízica e aclimatização de dois porta-enxertos de macieira micropropagados. Pesquisa Agropecuária Brasileira, v.37, p.177-184, 2002.

Marin, F. R.; Pellegrino, G. Q.; Assad, E. D.; Pinto, H. S.; Zullo Júnior, J. Agrometeorologia da cana-de-açúcar. In: INMET. (Org.). Agrometeorologia dos cultivos - Levantamento Sistemático de Informações Agrometeorológicas e Fitotécnicas. Brasília: INMET, v.1, 2009. p.109-130.

Meyer, L.; Serek, M.; Winkelmann, T. Protoplast isolation and plant regeneration of different genotypes of Petunia and Calibrachoa. Plant Cell Tissue Organ Culture, v.99, p.27-34, 2009.

Oliveira, R. A.; Daros, E.; Zambon, J. L. C.; Weber, H.; Ido, O. T. Bespalhok Filho, J. C.; Zuffellato-Ribas, K. C.; Silva, D. K. T. da. Área foliar em três cultivares de cana-de-açúcar e sua correlação com a produção de massa. Pesquisa Agropecuária Tropical, v.37, p.71-76, 2007.

Pereira, A. R.; Angelocci, L. R.; Sentelhas, P. C. Agrometeorologia. Fundamentos e aplicações práticas. Agropecuária: Guaíba. 2002. 478p.
Reis, L. S.; Souza, J. L. de; Azevedo, C. A. V. de. Evapotranspiração e coeficiente de cultivo do tomate caqui cultivado em ambiente protegido. Revista Brasileira de Engenharia Agrícola e Ambiental, v.13, p.289-296, 2009.

Santana, C. V. S.; Almeida, A. C.; Turco, S. H. N. Desempenho de cultivares de alface americana em ambientes sombreados na região do submédio São Francisco-BA. Revista Caatinga, v.22, p.60-64, 2009.

Souza Neto, O. N.; Dias, N. da S.; Atarassi, R. T.; Rebouças, J. R. L.; Oliveira, A. M. Produção de alface hidropônica e microclima de ambiente protegido sob malhas termorrefletoras. Revista Caatinga, v.23, p.84-90, 2010.

Tejera, N. A.; Rodés, R.; Ortega, E.; Campos, R.; Lluch, C. Comparative analysis of physiological characteristics and yield components in sugarcane cultivars. Field Crops Research, v.102, p.64-72, 2007.

Vasquéz, M. A. N.; Folegatti, M. V.; Dias, N. da S.; Silva, C. R. Efeito do ambiente protegido cultivado com melão sobre os elementos meteorológicos e sua relação com as condições externas. Revista Brasileira de Engenharia Agrícola e Ambiental, v.25, p.137-143, 2005.

Wiedenfeld, B.; Enciso, J. Sugarcane responses to irrigation and nitrogen in semiarid south Texas.Agronomy Journal, v.100, p.665-671, 2008. 